\title{
BMJ open Framework of policy recommendations for implementation of evidence-based practice: a systematic scoping review
}

\author{
Dirk T Ubbink, ${ }^{1,2}$ Gordon H Guyatt, ${ }^{3}$ Hester Vermeulen ${ }^{1,4}$
}

To cite: Ubbink DT, Guyatt GH, Vermeulen $\mathrm{H}$. Framework of policy recommendations for implementation of evidencebased practice: a systematic scoping review. BMJ Open 2013;3:e001881.

doi:10.1136/bmjopen-2012001881

- Prepublication history for this paper are available online. To view these files please visit the journal online (http://dx.doi.org/10.1136/ bmjopen-2012-001881).

Received 26 July 2012 Accepted 21 December 2012

This final article is available for use under the terms of the Creative Commons Attribution Non-Commercial 2.0 Licence; see http://bmjopen.bmj.com

${ }^{1}$ Department of Quality Assurance \& Process Innovation, Academic Medical Center, Amsterdam,

The Netherlands

${ }^{2}$ Department of Surgery,

Academic Medical Center, Amsterdam, The Netherlands ${ }^{3}$ Department of Clinical Epidemiology \& Biostatistics, McMaster University, Hamilton, Canada

${ }^{4}$ Amsterdam School of Health Professions, University of Amsterdam, Amsterdam, The Netherlands

Correspondence to Dr Dirk T Ubbink; d.ubbink@amc.nl

\begin{abstract}
Objectives: Evidence-based practice (EBP) may help improve healthcare quality. However, not all healthcare professionals and managers use EBP in their daily practice. We systematically reviewed the literature to summarise self-reported appreciation of EBP and organisational infrastructure solutions proposed to promote EBP.
\end{abstract}

Design: Systematic review. Two investigators independently performed the systematic reviewing process.

Information sources: MEDLINE, EMBASE and Cochrane Library were searched for publications between 2000 and 2011.

Eligibility criteria for included studies: Reviews and surveys of EBP attitude, knowledge, awareness, skills, barriers and facilitators among managers, doctors and nurses in clinical settings.

Results: We found 31 surveys of fairly good quality. General attitude towards EBP was welcoming. Respondents perceived several barriers, but also many facilitators for EBP implementation. Solutions were proposed at various organisational levels, including (inter)national associations and hospital management promoting EBP, pregraduate and postgraduate education, as well as individual support by EBP mentors on the wards to move EBP from the classroom to the bedside.

Conclusions: More than 20 years after its introduction, the EBP paradigm has been embraced by healthcare professionals as an important means to improve quality of patient care, but its implementation is still deficient. Policy exerted at microlevel , middlelevel and macrolevel, and supported by professional, educational and managerial role models, may further facilitate EBP.

\section{INTRODUCTION}

Evidence-based practice (EBP) provides a structure for the bedside use of research and consideration of patient values and preferences to optimise clinical decision-making and to improve patient care. ${ }^{12}$ EBP could potentially be used to improve quality of healthcare. ${ }^{3} 4$ In 2001, the Institute of Medicine's Quality

\section{ARTICLE SUMMARY}

\section{Article focus}

- Systematic review of the literature to summarise self-reported appreciation of evidence-based practice (EBP) and organisational infrastructure solutions proposed to promote EBP.

\section{Key messages}

- More than 20 years after its introduction, the EBP paradigm has been embraced by healthcare professionals as an important means to improve quality of patient care, but its implementation is still deficient.

- Policy exerted at microlevel, middlelevel and macrolevel, and supported by professional, educational and managerial role models, may further facilitate EBP.

Strengths and limitations of this study

- Worldwide overview of EBP appreciation and implementation strategies useful for all centres striving at a better EBP implementation.

- Self-reporting may have led to an overestimation of the results.

- The success of implementation strategies is still unclear.

Chasm series suggested EBP as one of the five core competencies for professional healthcare curricula. ${ }^{5}$ More recently, the growing societal demand for quality, safety, equality and accountability of healthcare and credentialing programmes as exerted by the Joint Commission International and Magnet hospitals have further promoted EBP. ${ }^{6} 7$ To date, hospital executive boards, insurance companies and consumers recognise that EBP may help prevent unsafe or inefficient practices, as part of a strategy to achieve quality improvement in healthcare. 8

Thus far, however, educational efforts have failed to achieve EBP at the bedside or in daily clinical problem-solving. While there is an ongoing debate on how to measure quality of care in general, attitude, awareness, knowledge or behaviour are relevant to 
understand application of EBP. Various questionnaires have been developed and used to appreciate these aspects (eg, McColl and Funk). ${ }^{9} 10$ This information suggested the implementation of EBP by doctors is hampered by a perceived lack of time, knowledge or EBP resources, ${ }^{9} 11$ whereas in the nursing realm EBP awareness, the body of knowledge and research utilisation, as well as managerial support are still developing. ${ }^{12} 13$ Based on these findings, many different recommendations for improvement have been proposed. Hence, it is timely to synthesise these recommendations for more structural organisational initiatives that may help overcome barriers and facilitate the uptake of EBP.

Therefore, the purpose of this study was to collect surveys of healthcare professionals' views on EBP in terms of self-reported attitude, knowledge, awareness, skills, barriers and behaviour regarding EBP among clinical doctors, nurses and managers, and to summarise proposed recommendations as derived from these views to improve the use of EBP. We subsequently used the findings of this review to propose a framework for implementation of EBP, tailor-made for different managerial levels and suitable to structurally facilitate and sustain evidence-based behaviour in clinical healthcare organisations.

\section{METHODS}

Literature search and study selection

Two of the authors (DTU, HV) searched the MEDLINE (using PubMed), EMBASE (using Ovid) and Cochrane databases from 2000 through 2011 for surveys or reviews of EBP attitude, knowledge, awareness, barriers and facilitators among nurses, physicians and managers in any clinical setting, that is, hospitals or other healthcare institutions, rather than general practice settings, on which a review has recently been published. ${ }^{14}$ Reference lists of the included studies and reviews were checked for additional eligible papers.

In brief, our search strategy was (evidence-based[ti] practice OR evidence-based medicine OR EBM OR EBP) and (questionnaire* OR survey OR inventory) and ((barriers OR McColl) AND (knowledge OR attitude* OR aware* OR behavio*) and (hospital* OR clinic* OR medical cent*)). No language restrictions were applied. Papers in foreign languages, if any, would be translated if possible.

We excluded studies in an undergraduate educational setting, studies with a purely qualitative design, studies not including clinical doctors or nurses, and those focusing on a specific disorder, guideline, model or technique. We focused on surveys rather than the latter studies, because merely following (particularly expertbased) guidelines or focusing on a specific disorder or technique does not necessarily indicate the general application of the five steps of EBP. Studies before 2000 were also excluded because in these years the EBP paradigm was in an early phase with a limited dispersion among healthcare professionals. Study selection and quality assessment was performed by two investigators independently.

\section{Quality assessment}

Judgment of the quality of the surveys was based on the number of centres and respondents involved, response rates and robustness of the questionnaires used (through pilot testing, prior validation or internal consistency based on a Cronbach's $\alpha$ ).

\section{Data items and synthesis of results}

By means of a structured form, two researchers independently extracted data on study characteristics (including country of origin, publication year, type and number of respondents and type of clinics included), questionnaires used and EBP characteristics studied, in particular EBP attitude, knowledge, skills and awareness, and perceived barriers and facilitating factors for EBP implementation. We extracted in a qualitative manner the reported recommendations, if any, on how to overcome these barriers or how to exploit facilitators. These were grouped into solutions to be executed at various organisational levels. After one investigator had entered the data in the database, these data were checked for accuracy by a second.

Meta-analysis was not planned because of the expected large range in geographical locations, caregivers investigated and questionnaires used. To summarise the results of the studies reporting on EBP attitudes and knowledge, we calculated the medians and report the ranges of the scores given for each item, for doctors and nurses separately. A possible association between response rate, year of publication and attitude towards EBP was calculated using Spearman's correlation coefficient. Statistical analysis was performed using PASW Statistics V.18.0 (IBM Inc, Armonk, New York, USA).

\section{RESULTS}

\section{Study inclusion}

Our search yielded 286 potentially relevant studies. We also found two recent reviews of studies on barriers towards EBP, ${ }^{15} 16$ from which other relevant studies were derived. Some more recent studies not included in these reviews were also found by hand-searching the references of included studies. Four surveys among medical postgraduates were excluded because these publications were in Chinese. In total, 31 studies that included 10798 respondents from 17 countries proved eligible (table 1). Studies represented nearly all continents, one-third $(11 / 31)$ were European and a quarter $(8 / 31)$ were from North America (figure 1). In four of the studies, EBP questions were administered in the context of an educational meeting. Seventeen studies focused specifically on doctors, 11 on nurses. Three of the 31 studies enrolled both doctors and nurses. ${ }^{24} 3043$ Wherever possible, results from doctors and nurses are presented separately. 
Table 1 Characteristics of included studies

\begin{tabular}{|c|c|c|c|c|c|}
\hline Author & Year & Country & $\begin{array}{l}\text { Teaching } \\
\text { hospital(s) }\end{array}$ & Respondents & $\begin{array}{l}\text { EBP aspects } \\
\text { studied* }^{*}\end{array}$ \\
\hline Ahmadi $^{17}$ & 2008 & Iran & Yes & $\begin{array}{l}\text { Internal medicine interns, residents and } \\
\text { fellows }\end{array}$ & $1,2,3$ \\
\hline Al-Almaie ${ }^{18}$ & 2004 & Saudi Arabia & No & Doctors from various specialties & 5 \\
\hline Al-Omari ${ }^{19}$ & 2009 & Jordan & Both & $\begin{array}{l}\text { Specialists, fellows, residents from various } \\
\text { specialties }\end{array}$ & $1,2,4,5,6$ \\
\hline Al-Omari $^{20}$ & 2006 & Saudi Arabia & Both & $\begin{array}{l}\text { Consultant physicians from various } \\
\text { specialties }\end{array}$ & $1,2,3,5$ \\
\hline $\operatorname{Amin}^{10}$ & 2007 & Ireland & Yes & Otorhinolaryngology surgical trainees & 1,4 \\
\hline Andersson $^{21}$ & 2007 & Sweden & Yes & Trainee and specialist paediatric nurses & 5 \\
\hline Brown $^{22}$ & 2009 & USA & Yes & Nurses from various specialties & 5,6 \\
\hline Brown $^{23}$ & 2010 & USA & Both & Nurses from various specialties & 5 \\
\hline Chiu $^{24}$ & 2010 & Taiwan & No & Doctors and nurses from various specialties & $1,2,5$ \\
\hline Gale $^{25}$ & 2009 & USA & No & $\begin{array}{l}\text { Staff nurses and nurse managers from } 8 \\
\text { ICUs }\end{array}$ & $1,5,6$ \\
\hline Gerrish $^{26}$ & 2008 & UK & Both & Nurses from various specialties & 5 \\
\hline Hadley $^{27}$ & 2007 & UK & No & Junior doctors & 1,2 \\
\hline Kitto $^{28}$ & 2007 & Australia & No & Surgeons & 5 \\
\hline Koehn $^{29}$ & 2008 & USA & No & Staff nurses, unit managers, clinical advisors & 1,5 \\
\hline $\mathrm{Lai}^{30}$ & 2010 & Malaysia & No & $\begin{array}{l}\text { Doctors, nursing and allied health staff before } \\
\text { attending EBM workshop }\end{array}$ & 1,5 \\
\hline Melnyk $^{31}$ & 2004 & USA & Unknown & Nurses before attending EBP workshops & 1,5 \\
\hline Mehrdad $^{32}$ & 2008 & Iran & Yes & Clinical nurses and nurse educators & 5,6 \\
\hline Mittal $^{33}$ & 2010 & India & No & $\begin{array}{l}\text { Surgical trainees attending continuing } \\
\text { education meeting }\end{array}$ & $1,2,3,4,5$ \\
\hline Nwagwu $^{34}$ & 2008 & Nigeria & Yes & Consultants in tertiary healthcare institutions & 2,3 \\
\hline Olivieri $^{35}$ & 2004 & Denmark & Yes & Doctors from various specialties & 2,4 \\
\hline Oranta ${ }^{36}$ & 2002 & Finland & No & Staff and ward nurses & 5,6 \\
\hline Palfreyman ${ }^{37}$ & 2003 & UK & Yes & $\begin{array}{l}\text { Nurses and physiotherapists from various } \\
\text { specialties }\end{array}$ & 2,5 \\
\hline Parahoo $^{38}$ & 2001 & N-Ireland & No & Medical and surgical nurses & $1,5,6$ \\
\hline Poolman 39 & 2007 & Netherlands & Unknown & Orthopaedic surgeons & $1,2,4$ \\
\hline Roth $^{40}$ & 2010 & Canada & Unknown & $\begin{array}{l}\text { English-speaking urology residents } \\
\text { participating in national review course }\end{array}$ & $2,3,4,5$ \\
\hline Scales $^{41}$ & 2008 & USA & Both & American Urology Association members & 1,5 \\
\hline Sur ${ }^{42}$ & 2006 & USA & Unknown & American Urology Association members & $1,3,4$ \\
\hline Ubbink $^{43}$ & 2011 & Netherlands & Yes & Doctors and nurses from various specialties & $1,2,3,4,5,6$ \\
\hline Ulvenes $^{44}$ & 2009 & Norway & Unknown & Reference panel of Norwegian physicians & 1,2 \\
\hline Upton $^{45}$ & 2005 & UK & Unknown & Doctors from various specialties & $2,5,6$ \\
\hline Veness $^{46}$ & 2003 & $\begin{array}{l}\text { Australia \& } \\
\text { New Zealand }\end{array}$ & Unknown & Radiation oncologists and registrars & $1,2,3,4,6$ \\
\hline
\end{tabular}

All studies applied postal or electronic questionnaires. To assess EBP attitude, knowledge, skills and awareness, most studies used the questionnaires developed by McColl, Upton or Estabrooks. ${ }^{9} 4748$ To assess EBP barriers and facilitators, most investigators used the Funk questionnaire. ${ }^{10}$ Half of the studies investigated both EBP attitude and barriers.

\section{Study characteristics}

The studies enrolled from $19^{10}$ to $1156^{24}$ respondents (median 273), consisting of doctors (residents, specialists) and nurses (ward and staff nurses, nurse managers and educators) from various clinical specialties. Seven of the 31 studies were conducted in a single centre. Response rates varied from $9 \%$ in nationwide surveys to $100 \%$ in questionnaires during trainings, with a median of $72 \%$. Twenty-four of the 31 studies (77\%) used robust questionnaires. So, overall quality of the included studies was good (table 2). Most studies addressed EBP attitude, skills and barriers (table 1).

\section{EBP attitude}

Fifteen of the 18 studies addressing EBP attitude used a (sometimes modified) McColl questionnaire. Based on these 15 studies, both doctors and nurses strongly felt that EBP improves patient care and is important for 


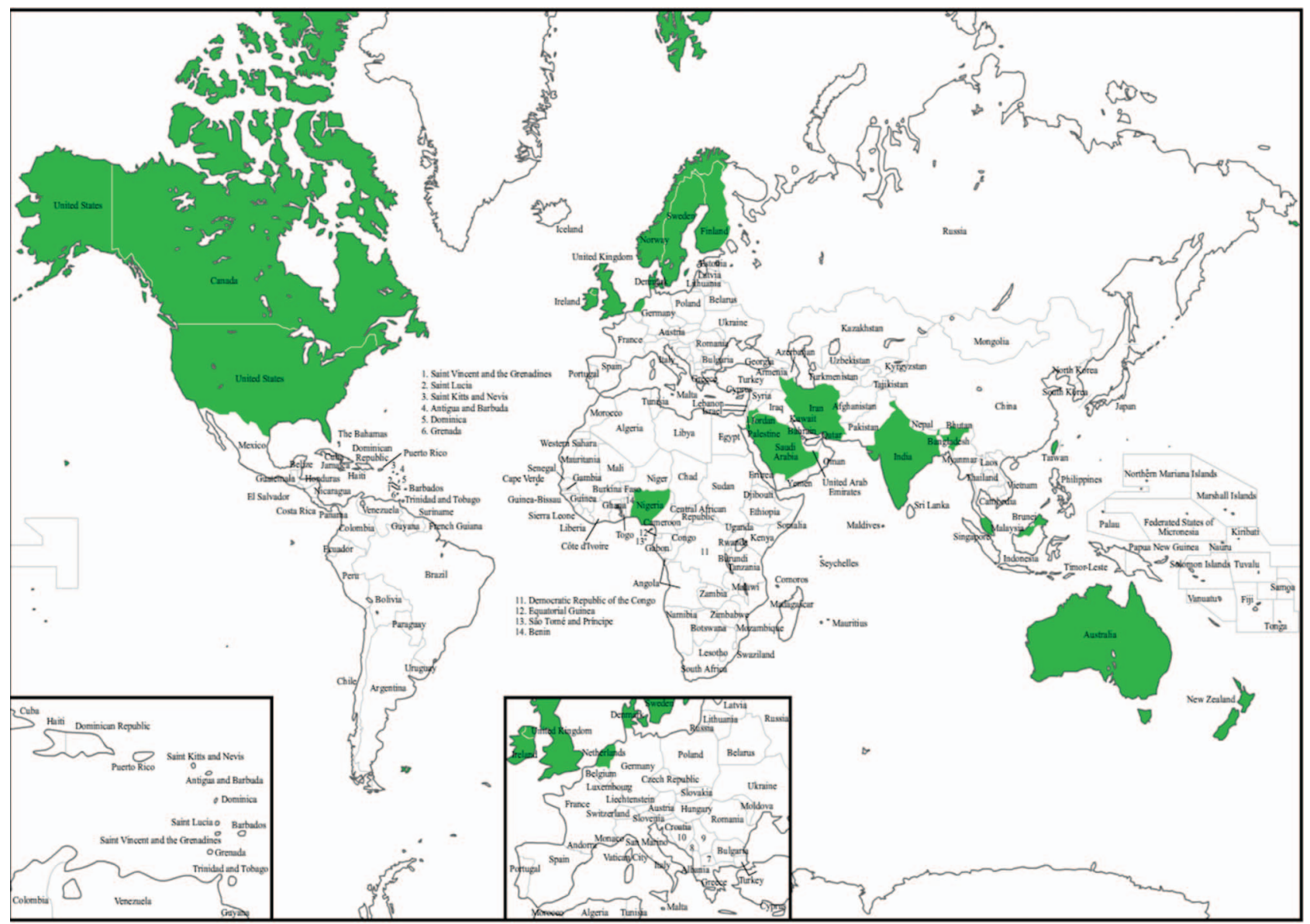

Figure 1 Countries from which studies were included.

their profession (table 3). Their overall attitude towards EBP was welcoming and appreciated the use of research evidence in daily clinical practice. However, they considered only half of their clinical practice to be evidence-based, although what they meant by this was, in most cases, not specified and unclear. These findings were consistent among the various countries. We did not find significant correlations between either response rate $(-0.112 ; \mathrm{p}=0.703)$ or year of publication $(-0.286$; $\mathrm{p}=0.321)$ and attitude towards EBP.

\section{EBP knowledge and skills}

The majority (median 64\%) of doctors and nurses reported they considered their EBP knowledge was insufficient. Similarly, a median of $70 \%$ of the respondents regarded their skills as insufficient, even in the most recent studies, and desired (more) EBP training. The percentage of doctors who had had EBP training ranged from 13\% (Indian surgical trainees) to $80 \%$ (Iranian internal medicine doctors). The most appropriate way, respondents thought to move towards EBP, was through evidence-based guidelines (median 68\%), evidence summaries (median 39\%) or critical appraisal skills (median $36 \%$ ).

PubMed accessibility was high (at least $88 \%$, except for India, $58 \%$ and Jordan, $70 \%$ ), either at home or at work. However, clinical decision-making was based on consulting textbooks and colleagues rather than by searching electronic databases.

Figure 2 depicts the knowledge of common EBP terms among doctors. Not all studies used the same EBP terms, but in general, half of the doctors had at least some knowledge about $83 \%(20 / 24)$ of the presented EBP terms. Three of the four terms they were unfamiliar with were meaningless dummy terms. Hence, the results of this part of the questionnaire seemed not biased by socially desired answering.

Only one study examined the nurses' knowledge of EBP terms (figure 3). ${ }^{43}$ Half of the nurses had at least some knowledge of $4(40 \%)$ of the 10 terms presented. The dummy terms appeared more familiar than terms like 'bias', 'power calculation' and 'number needed to treat', suggesting some socially desired answering.

\section{Awareness of common sources of evidence}

Eight studies addressed this issue (table 1). About a quarter of the responding doctors used the Cochrane Library (median 25\%), whereas 39\% of them were unaware of this database. The journal Evidence-Based Medicine was used by $14 \%$, but unknown in $34 \%$ of the doctors. Guidelines from the National Guideline Clearinghouse were used by $8 \%$ and unknown in $48 \%$, the 
Table 2 Quality characteristics of included studies

\begin{tabular}{|c|c|c|c|c|}
\hline Author & Centres (N) & Respondents (N) & Response rate (\%) & Questionnaire robustness* \\
\hline Ahmadi ${ }^{17}$ & 1 & 104 & 80 & + \\
\hline Al-Almaie ${ }^{18}$ & 3 & 273 & 67 & - \\
\hline Al-Omari ${ }^{19}$ & 5 & 386 & 97 & ++ \\
\hline Al-Omari ${ }^{20}$ & 9 & 178 & 86 & ++ \\
\hline $\operatorname{Amin}^{10}$ & Countrywide & 19 & 95 & ++ \\
\hline Andersson $^{21}$ & 2 & 113 & 80 & ++ \\
\hline Brown $^{22}$ & 1 & 458 & 45 & ++ \\
\hline Brown ${ }^{23}$ & 4 & 974 & 75 & ++ \\
\hline Chiu $^{24}$ & 61 & 1156 & 69 & ++ \\
\hline Gale $^{25}$ & 1 & 92 & 22 & ++ \\
\hline Gerrish $^{26}$ & 2 & 598 & 42 & ++ \\
\hline Hadley $^{27}$ & Several & 317 & 100 & ++ \\
\hline Kitto $^{28}$ & Several & 25 & 50 & + \\
\hline Koehn ${ }^{29}$ & 1 & 422 & 41 & ++ \\
\hline $\mathrm{Lai}^{30}$ & 2 & 144 & 72 & + \\
\hline Melnyk $^{31}$ & Several & 160 & 100 & + \\
\hline Mehrdad $^{32}$ & 15 & 410 & 70 & ++ \\
\hline Mittal $^{33}$ & 22 & 93 & 85 & ++ \\
\hline Nwagwu ${ }^{34}$ & 10 & 89 & 89 & - \\
\hline Olivieri ${ }^{35}$ & 1 & 225 & 60 & ++ \\
\hline Oranta ${ }^{36}$ & 2 & 253 & 80 & ++ \\
\hline Palfreyman ${ }^{37}$ & 1 & 106 & 24 & ++ \\
\hline Parahoo $^{38}$ & 10 & 479 & 53 & ++ \\
\hline Poolman ${ }^{39}$ & Countrywide & 367 & 60 & ++ \\
\hline Roth $^{40}$ & Several & 29 & 100 & ++ \\
\hline Scales $^{41}$ & Countrywide & 365 & 72 & ++ \\
\hline Sur ${ }^{42}$ & Countrywide & 714 & 9 & ++ \\
\hline Ubbink $^{43}$ & 1 & 701 & 72 & ++ \\
\hline Ulvenes $^{44}$ & Countrywide & 976 & 70 & - \\
\hline Upton $^{45}$ & Countrywide & 381 & 76 & ++ \\
\hline Veness $^{46}$ & Countrywide & 191 & 79 & ++ \\
\hline \multirow[t]{2}{*}{ Total } & $24(77 \%)$ & $25(81 \%)$ & $23(74 \%)$ & $24(77 \%)$ \\
\hline & $>1$ Centre & >100 Respondents & $\geq 60 \%$ Response & \\
\hline
\end{tabular}

ACP Journal Club used by $3 \%$ but unknown in $68 \%$ and the TRIP database was used by $15 \%$ and unknown in $71 \%$. Two studies showed this awareness was even less among nurses. ${ }^{24} 43$

\section{EBP barriers and facilitators}

Responses regarding the 29 barriers presented in Funk's questionnaire were usually dichotomised, that is, items scored as 'barrier' or 'large barrier' were counted as barriers. To give an overview of the barriers to EBP most frequently mentioned by doctors and nurses, we merged our data with the barriers found among nurses in the systematic review by Kajermo et $a l .{ }^{15}$ These barriers are summarised in table 4. Worldwide, EBP barriers were strikingly convergent, except the language barrier for non-English speaking countries and the limited access to electronic databases in some countries.

The major facilitating initiatives as desired by doctors and nurses were mostly collected through open questions. These facilitators include continuing EBP-teaching efforts in pregraduate and postgraduate curricula, constant involvement by colleagues in daily practice, staff and management support to learn and apply EBP in daily clinical practice, structural promotion and facilitation of EBP activities by the management and experts, and clear and easily accessible sources of evidence, protocols and guidelines.

\section{Recommendations reported to implement EBP}

All studies gave recommendations to overcome or address the identified barriers (table 5). From macrolevel, middlelevel and microlevel perspectives, that is, at (inter) national, hospital and ward levels, various solutions were proposed, ranging from advocating EBP by national regulatory bodies to specific interventions at ward level, including availability of computers and internet.

A qualitative evaluation of the recommendations shows they mainly focused on education for both pregraduates and postgraduates. The following aspects were considered important: how and with whom to build EBP curricula, tiered education based on needs assessments, 
Table 3 Attitudes of doctors and nurses towards EBP

\begin{tabular}{|c|c|c|}
\hline & $\begin{array}{l}\text { Doctors } \\
\text { Median (range) }\end{array}$ & $\begin{array}{l}\text { Nurses } \\
\text { Median (range) }\end{array}$ \\
\hline $\begin{array}{l}\text { Your current attitude towards EBP } \\
\text { Least positive (0) to Extremely positive (100) }\end{array}$ & 72.3 (49-97) & $66.7(55-85)$ \\
\hline $\begin{array}{l}\text { Attitude of your colleagues towards EBP } \\
\text { Least positive (0) to Extremely positive (100) }\end{array}$ & $61.0(41-89)$ & $48.0(48-48)$ \\
\hline $\begin{array}{l}\text { How useful are research findings in daily practice? } \\
\text { Useless (0) to Extremely useful (100) }\end{array}$ & $80.0(46-97)$ & $62.0(34-82)$ \\
\hline $\begin{array}{l}\text { What percentage of your clinical practice is evidence-based? } \\
0 \% \text { to } 100 \%\end{array}$ & $52.6(40-80)$ & $44.9(44-46)$ \\
\hline $\begin{array}{l}\text { Practicing EBP improves patient care } \\
\text { Completely disagree (0) to Fully agree (100) }\end{array}$ & $80.1(52-97)$ & $80.7(74-87)$ \\
\hline $\begin{array}{l}\text { EBP is of limited value in clinical practice, because a scientific basis is lacking } \\
\text { Completely disagree (0) to Fully agree (100) }\end{array}$ & $36.3(3-43)$ & $48.3(48-49)$ \\
\hline $\begin{array}{l}\text { Implementing EBP, however worthwhile as an ideal, places another demand on } \\
\text { already overloaded surgeons/nurses } \\
\text { Completely disagree (0) to Fully agree (100) }\end{array}$ & $51.4(37-56)$ & $55.2(17-61)$ \\
\hline $\begin{array}{l}\text { The amount of evidence is overwhelming } \\
\text { Completely disagree (0) to Fully agree (100) }\end{array}$ & $53.5(50-57)$ & No data \\
\hline $\begin{array}{l}\text { EBP fails in practice } \\
\text { Completely disagree (0) to Fully agree (100) }\end{array}$ & $39.7(15-84)$ & $41.0(39-63)$ \\
\hline $\begin{array}{l}\text { EBP is important for my profession } \\
\text { Completely disagree }(0) \text { to Fully agree (100) }\end{array}$ & $68.3(52-95)$ & $61.6(30-93)$ \\
\hline
\end{tabular}

learning by interaction and transfer of the education from the classroom to the bedside.

Regarding preconditions to strategically implement EBP, authors put emphasis on the role of the management in terms of facilitating prerequisites as well as creating a positive culture towards EBP. They also suggested that solutions to the problems encountered when implementing EBP should start with an analysis of the organisation to identify problems at both local and organisational levels to tailor the interventions.

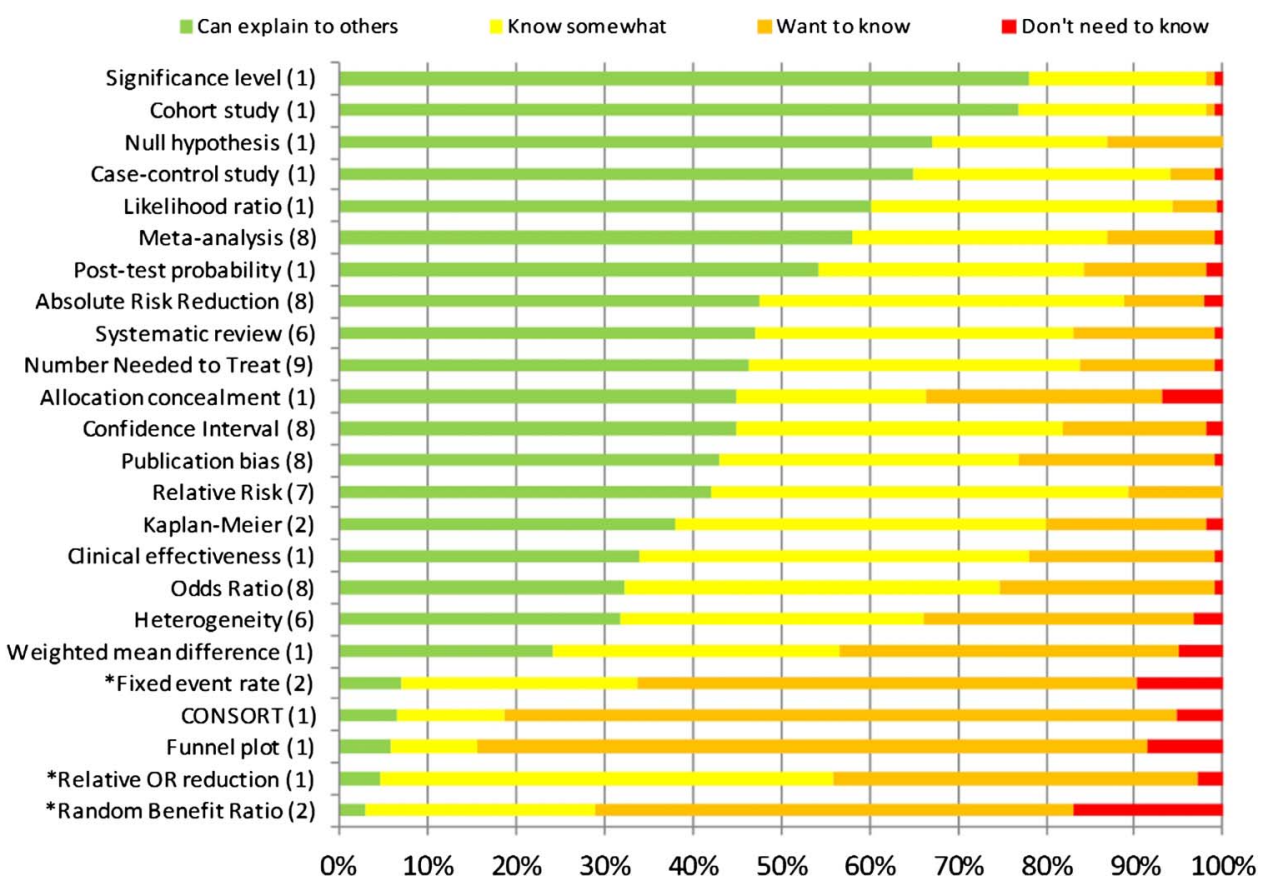

Figure 2 Doctors' knowledge of common evidence-based practice terms. The numbers between brackets indicate the number of studies that used this term. Terms with an asterisk are meaningless dummy terms. 
Figure 3 Nurses' knowledge of common evidence-based practice terms. Terms with an asterisk are meaningless dummy terms.

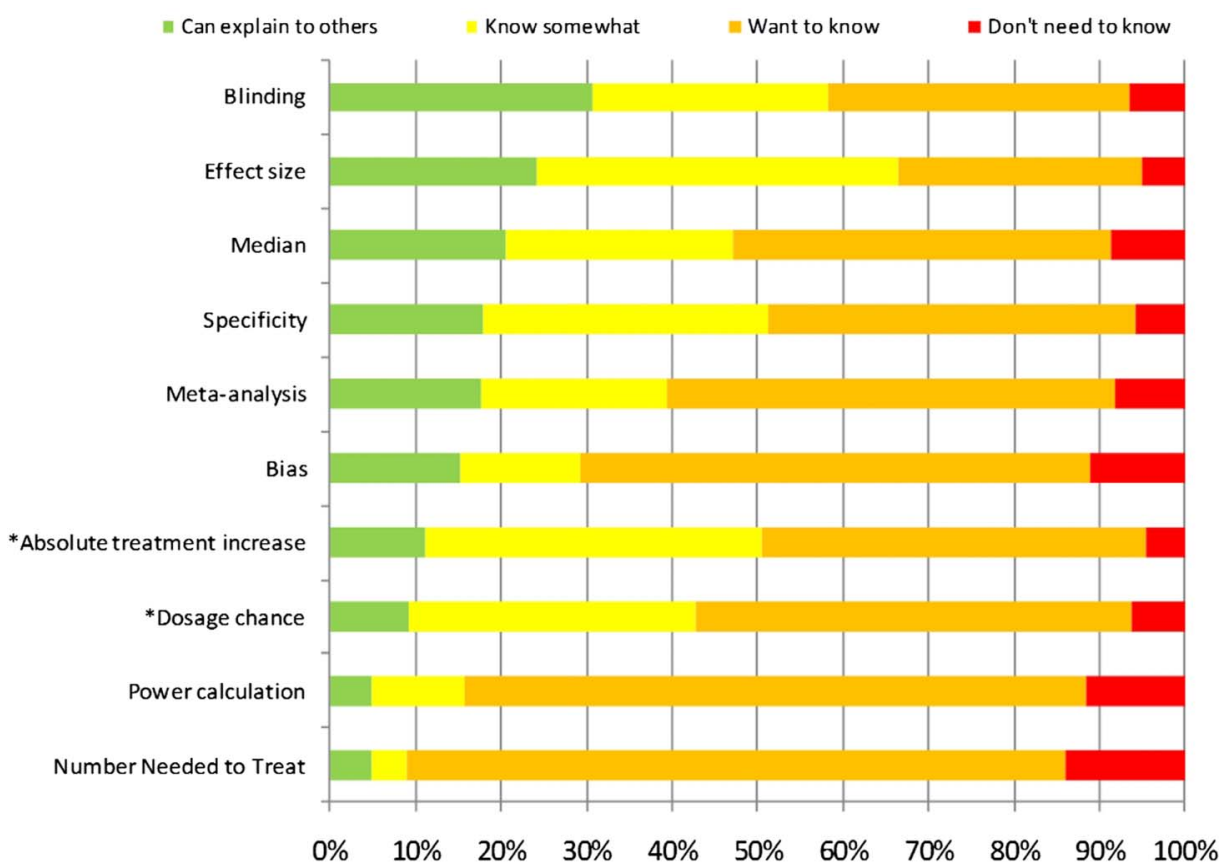

implementation issues. Some recommendations might also be useful as indicators to monitor the usage of EBP in daily clinical practice. Furthermore, this review could stimulate the testing of some of our recommendations through appropriately designed studies.

Although the majority of healthcare professionals appear quite EBP-minded and the uptake of EBP is progressing, ${ }^{49}$ important barriers are still obstructing the full implementation of EBP in daily clinical practice. These findings occur consistently among the various medical specialists and nurses alike, and in many specific settings and specialties throughout the world. However, Brown et al found in a multiple regression analysis that perceived barriers to research use predicted only a fraction of practice, attitude and knowledge/skills associated

Table 4 Barriers to apply EBP as mentioned by doctors and nurses

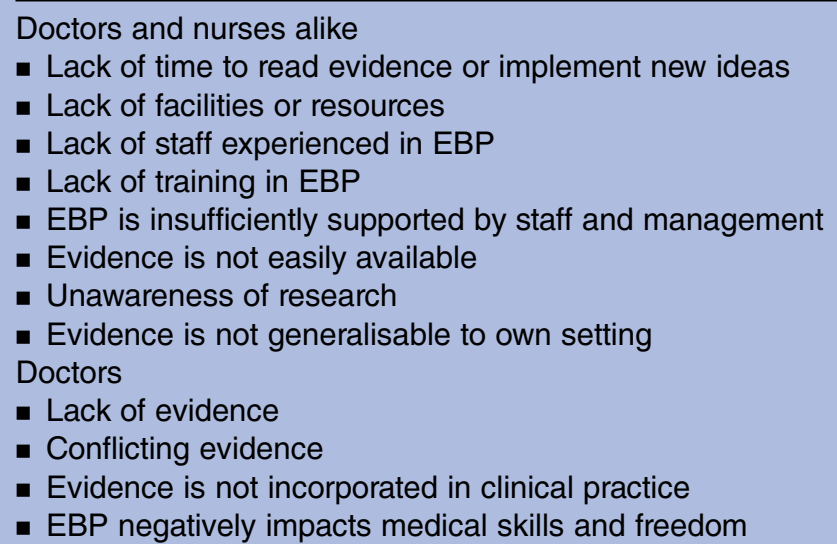

Nurses

- Evidence is written in foreign language

- Lack of authority to change practice

- Statistics or research is unintelligible

- Implications for practice are unclear

Stated are those ranked among the top ten in most studies.

EBP, evidence-based practice. 
Table 5 Structural incorporation of EBP at various levels as stated by the authors of the individual studies

\begin{tabular}{|c|c|c|c|}
\hline Level & Intervention by & Effect & Author \\
\hline \multirow[t]{5}{*}{ Worldwide } & International collaboration & $\begin{array}{l}\text { Expansion and acceleration of the } \\
\text { production and maintenance of } \\
\text { Cochrane Systematic Reviews }\end{array}$ & Oliveri \\
\hline & Global and international associations & Promotion of EBP & Olivieri \\
\hline & & Making EBP courses available & Sur \\
\hline & Scientific journals & Educational efforts & Poolman, Veness \\
\hline & & Publishing high quality research & Scales, Sur \\
\hline \multirow[t]{7}{*}{ National } & Governmental enforcement & $\begin{array}{l}\text { EBP in all undergraduate and } \\
\text { postgraduate healthcare educational } \\
\text { institutions }\end{array}$ & Melnyk, Ubbink \\
\hline & Installing and financing regulatory & Quality assurance & Al-Almaie \\
\hline & professional bodies & Practicing EBP & Melnyk \\
\hline & & Use of guidelines & Ubbink \\
\hline & Installing and financing a national institute & $\begin{array}{l}\text { Development of evidence based } \\
\text { guidelines }\end{array}$ & Al-Almaie \\
\hline & Arranging and financing & Free use of the Cochrane Library & Oliveri \\
\hline & $\begin{array}{l}\text { Policy makers, professional associations, } \\
\text { health insurance companies and } \\
\text { regulatory bodies }\end{array}$ & Promotion of EBP & $\begin{array}{l}\text { Scales, Oliveri, Poolman, } \\
\text { Melnyk }\end{array}$ \\
\hline \multirow[t]{6}{*}{$\begin{array}{l}\text { Board of } \\
\text { hospital } \\
\text { directors }\end{array}$} & Incorporating EBP in strategic aims & $\begin{array}{l}\text { Goals tailored on systematic } \\
\text { evaluations } \\
\text { Implementation of EBP and research } \\
\text { utilisation }\end{array}$ & Brown 2009, Ubbink \\
\hline & Installing research councils & High-quality research & Brown 2009, Melnyk \\
\hline & Allocating budget & High-quality research & Mehrdad \\
\hline & $\begin{array}{l}\text { Performing systematic evaluations during } \\
\text { working visits, quarterly meetings with } \\
\text { managers }\end{array}$ & $\begin{array}{l}\text { Increased hospital's level of EBP } \\
\text { implementation and quality of care }\end{array}$ & Ubbink \\
\hline & $\begin{array}{l}\text { Incorporating performance of EBP } \\
\text { activities by directors, managers and } \\
\text { administrators in annual interviews }\end{array}$ & $\begin{array}{l}\text { Increased hospital's level of EBP } \\
\text { implementation and quality of care }\end{array}$ & Ubbink \\
\hline & $\begin{array}{l}\text { Providing management, administrators } \\
\text { and directors with tools and means }\end{array}$ & Effective learning and practising EBP & Al Ohmari 2006, Lai \\
\hline \multirow[t]{8}{*}{ Managers } & Integrating EBP and policy setting & Evidence-based management & Al Ohmari 2009 \\
\hline & $\begin{array}{l}\text { Recruitment, selection, employment of } \\
\text { new personnel } \\
\text { Identifying EBP role models among } \\
\text { current personnel }\end{array}$ & EBP-minded working force & Ubbink, Brown 2010 \\
\hline & $\begin{array}{l}\text { Building an infrastructure and environment } \\
\text { with an atmosphere that supports. }\end{array}$ & $\begin{array}{l}\text { Effective tools for implementing, } \\
\text { learning and practising EBP }\end{array}$ & $\begin{array}{l}\text { Al-Almaie, Al Ohmari } \\
\text { 2006. Brown 2009, Chui. }\end{array}$ \\
\hline & $\begin{array}{l}\text { promotes and embraces EBP } \\
\text { (ie, incentives, prizes or rewards, } \\
\text { positive attitude) }\end{array}$ & $\begin{array}{l}\text { Knowledgeable (nurse) researchers, } \\
\text { (nurse) specialists, master' prepared } \\
\text { professionals, faculty, research } \\
\text { departments }\end{array}$ & $\begin{array}{l}\text { Gale, Gerrish, Melnyk, } \\
\text { Mehrdad, Mittal, Oranta, } \\
\text { Parahoo, Ubbink }\end{array}$ \\
\hline & Collaborating with educators & $\begin{array}{l}\text { Organisational barriers and } \\
\text { education addressed }\end{array}$ & Brown 2009 \\
\hline & Allocating budget & $\begin{array}{l}\text { (More) dedicated EBP personnel, } \\
\text { education, activities, computers and } \\
\text { facilities at each point of care. } \\
\text { Attending continuous education, } \\
\text { (inter)national conferences }\end{array}$ & $\begin{array}{l}\text { Brown 2009, Gale, } \\
\text { Gerrish, Mehrdad, Melnyk, } \\
\text { Lai }\end{array}$ \\
\hline & Provide non-patient hours to personnel & $\begin{array}{l}\text { Time for EBP activities and } \\
\text { implementation, changing practice, } \\
\text { and quality care development }\end{array}$ & $\begin{array}{l}\text { Brown 2009, Gale, } \\
\text { Mehrad, Palfeyman }\end{array}$ \\
\hline & $\begin{array}{l}\text { Regular evaluation (audit and feedback) } \\
\text { of ward-level EBP activities, knowledge, } \\
\text { skills, behaviour and research utilisation } \\
\text { during annual interviews }\end{array}$ & $\begin{array}{l}\text { Annual evaluation of implementing } \\
\text { EBP-activities }\end{array}$ & $\begin{array}{l}\text { Ahmandi, Al-Almaie, } \\
\text { Al Ohmari 2009, Ubbink }\end{array}$ \\
\hline
\end{tabular}


Table 5 Continued

\begin{tabular}{|c|c|c|c|}
\hline Level & Intervention by & Effect & Author \\
\hline \multirow[t]{9}{*}{ Educators } & $\begin{array}{l}\text { Incorporating and inflating time spent on } \\
\text { EBP by refining and modifying curriculum } \\
\text { and education style in postgraduate and } \\
\text { undergraduate medical and nursing } \\
\text { curricula }\end{array}$ & $\begin{array}{l}\text { Each non-academic degree } \\
\text { professional produces a Cochrane } \\
\text { Systematic review } \\
\text { Improved audit and feedback, } \\
\text { systematic evaluation, and needs } \\
\text { assessment } \\
\text { Tiered, feasible and realistic } \\
\text { education }\end{array}$ & $\begin{array}{l}\text { Ahmandi, Al-Almaie, } \\
\text { Al-Ohmari 2006, Amin, } \\
\text { Andersson, Brown 2009, } \\
\text { Gale, Gerrish, Hadley, } \\
\text { Kitto, Koehn, Lai, } \\
\text { Mehrdad, Melnyk, Mittal, } \\
\text { Nwagwu, Oliveri, Parahoo, } \\
\text { Poolman, Scales, Sur, } \\
\text { Ubbink, Upton }\end{array}$ \\
\hline & $\begin{array}{l}\text { Formulating the curriculum and educating } \\
\text { in collaboration with healthcare } \\
\text { professionals }\end{array}$ & EBP integration & $\begin{array}{l}\text { Al-Almaie, Al Ohmari } \\
\text { 2006, Brown 2009, Gale, } \\
\text { Gerrish, Lai }\end{array}$ \\
\hline & $\begin{array}{l}\text { Interactive, face-to-face education in } \\
\text { clinical practice and at the bed side }\end{array}$ & EBP integration & $\begin{array}{l}\text { Ahmandi, Al-Almaie, Amin, } \\
\text { Al Ohmari 2006, Kitto, } \\
\text { Melnyk, Poolman }\end{array}$ \\
\hline & Interactive education & E-learning modules & Kitto, Poolman, Ubbink \\
\hline & $\begin{array}{l}\text { EBP internship programme } \\
\text { In-service training }\end{array}$ & Extended EBP education & $\begin{array}{l}\text { Brown } 2009 \\
\text { Gerrish }\end{array}$ \\
\hline & $\begin{array}{l}\text { Accessing, appraising and interpreting } \\
\text { guidelines, research and protocols, basic } \\
\text { statistical analysis, research training, } \\
\text { IT-technology, quality development, } \\
\text { change management, being a role model, } \\
\text { English language }\end{array}$ & Optimum content of education & $\begin{array}{l}\text { Al Ohmari 2006, } \\
\text { Andersson, Gerrish, Lai, } \\
\text { Mehrdad, Mittal, Nwagwu, } \\
\text { Oranta, Parahoo }\end{array}$ \\
\hline & Educating all educators in EBP & Well-equipped educators & Oranta \\
\hline & $\begin{array}{l}\text { Emphasising professionals' own } \\
\text { responsibility }\end{array}$ & $\begin{array}{l}\text { Professional skills and competencies } \\
\text { maintained }\end{array}$ & Oranta \\
\hline & Evaluating effectiveness of EBP teaching & Optimum EBP education & Ulvenes, Veness \\
\hline \multirow[t]{6}{*}{$\begin{array}{l}\text { Faculty and } \\
\text { researchers }\end{array}$} & $\begin{array}{l}\text { Documenting, analysing and interpreting } \\
\text { the effectiveness of actions undertaken }\end{array}$ & EBP implementation & Brown 2009 \\
\hline & $\begin{array}{l}\text { Support professionals in clinical setting by } \\
\text { simple and clear (written) communication }\end{array}$ & EBP implementation & Mehrdad, Brown 2009 \\
\hline & Using a variety of strategies & $\begin{array}{l}\text { Dissemination of research findings } \\
\text { Valorisation of results in practice }\end{array}$ & $\begin{array}{l}\text { Brown } 2009 \\
\text { Melnyk }\end{array}$ \\
\hline & $\begin{array}{l}\text { Close collaboration with practicing } \\
\text { professionals }\end{array}$ & $\begin{array}{l}\text { Shared language and understanding } \\
\text { of concepts } \\
\text { Actual relevant clinical questions are } \\
\text { addressed }\end{array}$ & Oranta \\
\hline & Being a role model & Real-life discussions about patients & Poolman \\
\hline & Performing and promoting research & Well-designed high quality research & Scales, Sur \\
\hline \multirow[t]{6}{*}{ Services } & Medical library facilities & $\begin{array}{l}\text { Service for searching databases } \\
\text { Clinical letters, journals and } \\
\text { guidelines }\end{array}$ & $\begin{array}{l}\text { Al Ohmari 2006, Melnyk, } \\
\text { Mittal, Parahoo, Ubbink, } \\
\text { Al Ohmari 2006, }\end{array}$ \\
\hline & $\begin{array}{l}\text { Computer and internet facilities at point of } \\
\text { care, ward, or in EBP suites }\end{array}$ & $\begin{array}{l}\text { Liberal access to databases } \\
\text { Tailored to EBP level of } \\
\text { professionals }\end{array}$ & $\begin{array}{l}\text { Al Ohmari 2006, Gale, Lai, } \\
\text { Mehrdad, Nwagwu, Chui, } \\
\text { Melnyk, Ubbink }\end{array}$ \\
\hline & $\begin{array}{l}\text { Content management system allowing } \\
\text { access to guidelines, protocols, critically } \\
\text { appraised topics and condensed } \\
\text { recommendations }\end{array}$ & $\begin{array}{l}\text { User-friendly and reliable, readable } \\
\text { and pre-appraised information } \\
\text { Provide work-based information }\end{array}$ & $\begin{array}{l}\text { Al Ohmari 2009, Gerrish, } \\
\text { Lai, Ubbink }\end{array}$ \\
\hline & $\begin{array}{l}\text { Computer based decision support system } \\
\text { with priority to systematic reviews }\end{array}$ & $\begin{array}{l}\text { Computer-based guideline } \\
\text { implementation } \\
\text { Alerts and reminders }\end{array}$ & Al-Almaie, Al Ohmari 2009 \\
\hline & Accessible critical appraisal committee & $\begin{array}{l}\text { Easy assessment of relevant } \\
\text { literature }\end{array}$ & Mehrdad \\
\hline & Implementation guidance & $\begin{array}{l}\text { Overcomes obstacles to implement } \\
\text { EBP or recommendation } \\
\text { Change in practice }\end{array}$ & Chui, Mehrdad \\
\hline
\end{tabular}




\begin{tabular}{|c|c|c|c|}
\hline Level & Intervention by & Effect & Author \\
\hline \multirow[t]{3}{*}{$\begin{array}{l}\text { Local } \\
\text { workplace }\end{array}$} & $\begin{array}{l}\text { Journal clubs, grand rounds, handovers, } \\
\text { regular (research) meetings }\end{array}$ & EBP implementation & Oranta, Poolman, Ubbink \\
\hline & $\begin{array}{l}\text { Dedicated time and personnel for EBP } \\
\text { activities }\end{array}$ & Individual support at the units & Andersson, Ubbink \\
\hline & $\begin{array}{l}\text { Easy access to EBP mentors, change } \\
\text { mentors, innovators and educators, } \\
\text { computers, databases and relevant EBP } \\
\text { websites or links }\end{array}$ & EBP implementation & $\begin{array}{l}\text { Al-Almaie, Chui, Gale, Lai, } \\
\text { Mehrdad, Ubbink, Veness }\end{array}$ \\
\hline \multirow[t]{11}{*}{ Culture } & Emphasis on EBP in day-to-day practice & & Amin \\
\hline & Emphasis on patient benefit of EBP & & Gale, Melnyk \\
\hline & $\begin{array}{l}\text { Sharing experience, knowledge and } \\
\text { support }\end{array}$ & & Andersson \\
\hline & $\begin{array}{l}\text { Activating autonomy and empower nurses } \\
\text { to influence change }\end{array}$ & & Brown 2009, Gerrish \\
\hline & Shared governance structures & & Brown 2009 \\
\hline & Engaging in research & & Gerrish \\
\hline & $\begin{array}{l}\text { Willingness to facilitate the process of } \\
\text { implementing }\end{array}$ & & Koehn \\
\hline & $\begin{array}{l}\text { Innovative strategies including a culture of } \\
\text { research implementation }\end{array}$ & & Mehrdad \\
\hline & $\begin{array}{l}\text { Displaying interest and belief in value of } \\
\text { research utilization }\end{array}$ & & Mittal \\
\hline & $\begin{array}{l}\text { Enlightening professionals to use EBP in } \\
\text { decision making }\end{array}$ & & Nwagwu \\
\hline & Supportive culture to research & & Parahoo \\
\hline
\end{tabular}

with EBP. ${ }^{23}$ Apparently, the most frequently reported barriers are not necessarily the main reason for a poor implementation of EBP. Rather, a change in mind set seems indicated among the various healthcare professionals who perceive these barriers. Additional barriers to EBP implementation may lie at the organisational level. ${ }^{4}$ Hence, an integrative approach, involving all professionals and supported by initiatives from various organisational levels, may be a more fitting solution.

An integrative approach to overcome perceived barriers to EBP has also been suggested by other authors, ${ }^{50}$ who reasoned that the best implementation strategy should be a multifocal, comprehensive programme involving all professionals and should be tailored to their desires and perceived barriers. A systematic review of 235 studies on (multifaceted) guideline implementation strategies presented imperfect evidence to support decisions about which guideline dissemination and implementation strategies are likely to be efficient under different circumstances. ${ }^{51}$ Opinion leaders and role models appear to have a key function. ${ }^{52}$ A recent systematic review, comprising seven observational studies, described the relation between EBP implementation and leadership among nurses. ${ }^{53}$ The evidence suggested that initiatives on the level of leadership, organisation and culture are pivotal for the process of implementing EBP in nursing. However, available evidence for the effectiveness of organisational infrastructures in promoting evidence-based nursing is scarce. ${ }^{4}$ In the medical realm, such evidence is also limited. ${ }^{28} 54-56$

Other frameworks or multidimensional programmes have been proposed to improve research utillisation, ${ }^{13}$ or to stimulate the use of EBP by nurses, ${ }^{57}$ or on specific wards. ${ }^{58}$ Others have promoted a dedicated research agenda, ${ }^{59}$ integrated EBP education ${ }^{56}{ }^{60}$ or the implementation of EBP in specific medical specialties. ${ }^{16} 61$ Clinically integrated rather than stand-alone EBP teaching initiatives have been shown to improve EBP behaviour and may therefore help implement EBP in clinical practice. ${ }^{62}$ These initiatives per se seem defective because none of these aspects can be omitted to arrive at a truly evidence-based healthcare: if EBP education falls short, managers do not facilitate EBP activities, doctors do not apply EBP in their daily practice or nurses are lagging behind in EBP knowledge, optimum evidence-based healthcare eventually will not (fully) reach the patients who deserve it. This has been one of the reasons why a European teaching project has started to incorporate evidence-based medicine in clinical practice. ${ }^{63}$

\section{LIMITATIONS}

Although not all studies found were performed in teaching hospitals, the majority may have been performed in centres that already had the aim, or were in the process of implementing EBP. Many other centres are likely to 
be lagging further behind. However, higher response rates were not associated with more positive attitudes towards EBP. Given the settings and types of respondents in the studies included here, the inferences of our review appear primarily valid for clinical doctors and nurses from various specialties in centres that aim at implementing EBM.

Second, the questionnaires used were self-reported and response rates varied considerably. For both reasons, our results may overestimate enthusiasm, knowledge and uptake of EBP. On the other hand, the framework of implementation recommendations we derived from these studies may be useful for all centres striving at a better EBP implementation.

Third, in our review, we searched for surveys of EBP attitude, knowledge, awareness, barriers and facilitators rather than studies specifically focusing on testing alternatives to improve implementation of EBP. Such studies, however, are rare. ${ }^{4} 83$ The implementation factors these studies mentioned also became clear from our review, while the success of these implementation strategies is still unclear. One of the reasons for this is the absence of a valid means of assessing actual EBP behaviour during daily practice. ${ }^{62} 64-66$

Finally, we realise EBP is an essential but not the sole factor to improve quality of care. Even if clinicians are aware of available evidence, the right thing to do does not always happen. Continuous quality improvement strategies also involve active implementation of available evidence and existing guidelines. Nevertheless, a critical evidence-based attitude towards current practice remains the first step towards quality improvement.

\section{CONCLUSION}

Our review of all available surveys on the barriers for, and promotion of, EBP activities as perceived by clinical doctors and nurses suggests that EBP implementation needs a multilevel approach, involving interventions in the policy-making, managerial, educational and practical areas. We offer a summary of the suggested interventions at these different levels. These may be used not only to implement, but also to monitor the usage of EBP in daily clinical practice. This requires a joint effort and cultural change within the whole healthcare organisation, but is likely to result in a better quality of care.

Contributors DTU and HV conceived the idea of the study and were responsible for its design. They also performed data acquisition and analysis. DU drafted the paper, HV revised it critically. GHG contributed substantially to the draft of the article, provided input to the data analysis and the interpretation of the results, and revised the manuscript critically. All authors gave approval for the final version.

Funding This research received no specific grant from any funding agency in the public, commercial or not-for-profit sectors.

Competing interests None.

Provenance and peer review Not commissioned; externally peer reviewed.

Data sharing statement There are no additional data available.

\section{REFERENCES}

1. Sackett DL, Rosenberg WM, Gray JA, et al. Evidence based medicine: what it is and what it isn't. BMJ 1996;312:71-2.

2. Evidence-Based Medicine Working Group. Evidence-based medicine. A new approach to teaching the practice of medicine. JAMA 1992;268:2420e5.

3. Claridge JA, Fabian TC. History and development of evidence-based medicine. World J Surg 2005;29:547-53.

4. Flödgren G, Rojas-Reyes MX, Cole N, et al. Effectiveness of organisational infrastructures to promote evidence-based nursing practice. Cochrane Database Syst Rev 2012;2:CD002212.

5. Committee on Quality of Health Care in America, Institute of Medicine. Crossing the quality chasm: a new health system for the 21st century. Washington, DC: National Academies Press, 2001.

6. Nyweide DJ, Anthony DL, Chang CH, et al. Seniors' perceptions of health care not closely associated with physician supply. Health Aff (Millwood) 2011;30:219-27.

7. Balakas $K$, Potter P, Pratt E, et al. Evidence equals excellence: the application of an evidence-based practice model in an academic medical center. Nurs Clin North Am 2009;44:1-10, ix.

8. Glasziou P, Ogrinc G, Goodman S. Can evidence-based medicine and clinical quality improvement learn from each other? BMJ Qual Saf 2011;20:113-17.

9. McColl $A$, Smith $H$, White $P$, et al. General practitioner's perceptions of the route to evidence based medicine: a questionnaire survey. BMJ 1998;316:361-5.

10. Funk SG, Champagne MT, Wiese RA, et al. BARRIERS: the barriers to research utilization scale. Appl Nurs Res 1991;4:39-45.

11. McCaughey D, Bruning NS. Rationality versus reality: the challenges of evidence-based decision making for health policy makers. Implement Sci 2010;5:39.

12. Carlson CL, Plonczynski DJ. Has the BARRIERS Scale changed nursing practice? An integrative review. J Adv Nurs 2008;63:322-33.

13. Tagney $\mathrm{J}$, Haines $\mathrm{C}$. Using evidence-based practice to address gaps in nursing knowledge. Br J Nurs 2009;18:484-9.

14. Zwolsman S, te Pas E, Hooft L, et al. Barriers to GPs' use of evidence-based medicine: a systematic review. Br J Gen Pract 2012;62:e511-21.

15. Kajermo KN, Boström AM, Thompson DS, et al. The BARRIERS scale-the barriers to research utilization scale: a systematic review. Implem Sci 2010;5:32.

16. Van Dijk N, Hooft L, Wieringa-de Waard M. What are the barriers to resident's practicing evidence-based medicine? A systematic review. Acad Med 2010;85:1163-70.

17. Ahmadi-Abhari S, Soltani A, Hosseinpanah F. Knowledge and attitudes of trainee physicians regarding evidence-based medicine: a questionnaire survey in Tehran, Iran. J Eval Clin Pract 2008:14:775-9.

18. Al-Almaie SM, Al-Baghli N. Barriers facing physicians practicing evidence-based medicine in Saudi Arabia. J Contin Educ Health Prof 2004;24:163-70.

19. Al Omari M, Khader $\mathrm{Y}$, Jadallah $\mathrm{K}$, et al. Evidence-based medicine among hospital doctors in Jordan: awareness, attitude and practice. $J$ Eval Clin Pract 2009;15:1137-41.

20. Al-Omari FK, Al-Asmary SM. Attitude, awareness and practice of evidence-based medicine among consultant physicians in western region of Saudi Arabia. Saudi Med J 2006;27:1887-93.

21. Andersson N, Jylli L, Kajermo KN, et al. Nurses in paediatric careself-reported professional self and perceived research utilization. Scand J Caring Sci 2007;21:426-33.

22. Brown $C E$, Wickline MA, Ecoff $L$, et al. Nursing practice, knowledge, attitudes and perceived barriers to evidence-based practice at an academic medical center. J Adv Nurs 2009;65:371-81.

23. Montori VM, Guyatt GH. Progress in evidence-based medicine. JAMA 2008;300:1814-16.

24. Chiu YW, Weng YH, Lo HL, et al. Comparison of evidence-based practice between physicians and nurses: a national survey of regional hospitals in Taiwan. J Contin Educ Health Prof 2010;30:132-8.

25. Gale B, Schaffer MA. Organizational readiness for evidence-based practice. J Nurs Admin 2009;39:91-7.

26. Gerrish K, Ashworth P, Lacey A, et al. Developing evidence-based practice: experiences of senior and junior clinical nurses. J Adv Nurs 2008;62:62-73.

27. Hadley JA, Wall D, Khan KS. Learning needs analysis to guide teaching evidence-based medicine: knowledge and beliefs amongst trainees from various specialties. BMC Med Educ 2007;7:11.

28. Oude Rengerink K, Thangaratinam S, Barnfield G, et al. How can we teach EBM in clinical practice? An analysis of barriers to implementation of on-the-job EBM teaching and learning. Med Teach 2011;33:e125-30. 
29. Koehn ML, Lehman K. Nurses' perceptions of evidence-based nursing practice. J Adv Nurs 2008;62:209-15.

30. Lai NM, Teng CL, Lee ML. The place and barriers of evidence-based practice: knowledge and perceptions of medical, nursing and allied health practitioners in Malaysia. BMC Res Notes 2010;3:279.

31. Melnyk BM, Fineout-Overholt E, Fishbeck Feinstein N, et al. Nurses perceived knowledge, beliefs, skills, and needs regarding evidence-based practice: implications for accelerating the paradigm shift. Worldviews Evid Based Nurs 2004;1:185-93.

32. Mehrdad N, Salsali M, Kazemnejad A. The spectrum of barriers to and facilitators of research utilization in Iranian nursing. J Clin Nurs 2008;17:2194-202.

33. Mittal R, Peraketh B. Evidence-based surgery: knowledge, attitudes, and perceived barriers among surgical trainees. J Surg Educ 2010;67:278-82.

34. Nwagwu W. Levels of consciousness and awareness about evidence-based medicine among consultants in tertiary health care institutions in Nigeria. Health Info Libr J 2008;25:278-87.

35. Oliveri RS, Gluud C, Wille-Jørgenson PA. Hospital doctors' self-rated skills in and use of evidence-base medicine-a questionnaire survey. J Eval Clin Pract 2004;10:219-26.

36. Oranta O, Routalaso P, Hupli M. Barriers to and facilitators of research utilization among Finnish registered nurses. J Clin Nurs 2002;11:205-13.

37. Palfreyman S, Tod A, Doyle J. Comparing evidence-based practice of nurses and physiotherapists. Br J Nurs 2003;12:246-53.

38. Parahoo K, McCaughan EM. Research utilization among medical and surgical nurses: a comparison of their self reports and perceptions of barriers and facilitators. J Nurs Manag 2001;9:21-30.

39. Poolman RW, Sierevelt IN, Farrokhyar F, et al. Perceptions and competence in evidence-based medicine: are surgeons getting better? A questionnaire survey of members of the Dutch Orthopaedic Association. J Bone Joint Surg Am 2007;89:206-15.

40. Roth K, Siemens DR. The status of evidence-based medicine education in urology residency. Can Urol Assoc 2010;4:114-20.

41. Scales CD, Voils Cl, Fesperman SF, et al. Barriers to the practice of evidence-based urology. J Urol 2008;179:2345-50.

42. Sur RL, Scales CD, Preminger GM, et al. Evidence-based medicine: a survey of American Urological Association members. J Urol 2006;176:1127-34.

43. Ubbink DT, Vermeulen $\mathrm{H}$, Knops AM, et al. Implementation of evidence-based practice: outside the box, throughout the hospital. Neth J Med 2011;69:87-94.

44. Ulvenes LV, Aasland O, Nylenna M, et al. Norwegian physicians' knowledge of and opinions about evidence-based medicine: cross-sectional study. PLoS One 2009;4:e7828.

45. Upton D, Upton P. Knowledge and use of evidence-based practice of GOPs and hospital doctors. J Eval Clin Pract 2005;12:376-84.

46. Veness M, Rikard-Bell G, Ward J. Views of Australian and New Zealand radiation oncologists and registrars about evidence-based medicine and their access to internet based sources of evidence. Australas Radiol 2003;47:409-15.
47. Upton D, Upton P. Development of an evidence-based practice questionnaire for nurses. J Adv Nurs 2006;53:454-8.

48. Estabrooks CA. Mapping the research utilization field in nursing. Can J Nurs Res 1999;31:53-72.

49. Amin M, Saunders JA, Fenton JE. Pilot study of the knowledge and attitude towards evidence-based medicine of otolaryngology higher surgical trainees. Clin Otolaryngol 2007;32:120-35.

50. Brown CC, Ecoff L, Kim SC, et al. Multi-institutional study of barriers to research utilization and evidence-based practice among hospital nurses. J Clin Nurs 2010;19:1944-51.

51. Grol R, Grimshaw J. From best evidence to best practice: effective implementation of change in patients' care. Lancet 2003;362:1225-30.

52. Grimshaw J, Eccles M, Thomas R, et al. Toward evidence-based quality improvement. Evidence (and its limitations) of the effectiveness of guideline dissemination and implementation strategies 1966-1998. J Gen Intern Med 2006;21 (Suppl 2):S14-20.

53. Flödgren $\mathrm{G}$, Parmelli $\mathrm{E}$, Doumit $\mathrm{G}$, et al. Local opinion leaders: effects on professional practice and health care outcomes. Cochrane Database Syst Rev 2011;8:CD000125.

54. Sandström B, Borglin G, Nilsson R, et al. Promoting the implementation of evidence-based practice: a literature review focusing on the role of nursing leadership. Worldviews Evid Based Nurs 2011;8:212-23.

55. Pronovost PJ, Berenholtz SM, Dorman T, et al. Evidence-based medicine in anesthesiology. Anesth Analg 2001;92:787-94.

56. Swanson JA, Schmitz D, Chung KC. How to practice evidence-based medicine. Plast Reconstr Surg 2010;126:286-94.

57. Kitto S, Petrovic A, Gruen RL, et al. Evidence-based medicine training and implementation in surgery: the role of surgical cultures. J Eval Clin Pract 2011;17:819-26.

58. Olade RA. Strategic collaborative model for evidence-based nursing practice. Worldviews Evid Based Nurs 2004;1:60-8.

59. Aitken LM, Hackwood B, Crouch S, et al. Creating an environment to implement and sustain evidence based practice: a developmental process. Aust Crit Care 2011;24:244-54

60. Neugebauer EA, Morino M, Habermalz B. Surgical research or comic opera? Let's give answers! Surg Endosc 2008;22:1411-12.

61. Glasziou P, Burls A, Gilbert R. Evidence based medicine and the medical curriculum. BMJ 2008;337:a1253.

62. Ubbink DT, Legemate DA. Evidence-based surgery. Br J Surg 2004:91:1091-2.

63. Coomarasamy A, Khan KS. What is the evidence that postgraduate teaching in evidence based medicine changes anything? A systematic review. BMJ 2004;329:1017.

64. Thangaratinam S, Barnfield G, Weinbrenner S, et al. Teaching trainers to incorporate evidence-based medicine (EBM) teaching in clinical practice: the EU-EBM project. BMC Med Educ 2009;9:59.

65. Shaneyfelt T, Baum KD, Bell D, et al. Instruments for evaluating education in evidence-based practice: a systematic review. JAMA 2006;296:1116-27.

66. Oude Rengerink K, Zwolsman SE, Ubbink DT, et al. Tools to assess evidence-based practice behaviour among healthcare professionals-a systematic review. Evid Based Med 2013;in press. 